\title{
Development from childhood to adulthood increases morphological and functional inter-individual variability in the right superior temporal cortex
}

Citation for published version (APA):

Bonte, M. L., Frost, M., Rutten, S., Ley, A., Formisano, E., \& Goebel, R. (2013). Development from childhood to adulthood increases morphological and functional inter-individual variability in the right superior temporal cortex. Neuroimage, 83, 739-750. https://doi.org/10.1016/j.neuroimage.2013.07.017

Document status and date:

Published: 01/01/2013

DOI:

10.1016/j.neuroimage.2013.07.017

Document Version:

Publisher's PDF, also known as Version of record

Document license:

Taverne

Please check the document version of this publication:

- A submitted manuscript is the version of the article upon submission and before peer-review. There can be important differences between the submitted version and the official published version of record.

People interested in the research are advised to contact the author for the final version of the publication, or visit the DOI to the publisher's website.

- The final author version and the galley proof are versions of the publication after peer review.

- The final published version features the final layout of the paper including the volume, issue and page numbers.

Link to publication

\footnotetext{
General rights rights.

- You may freely distribute the URL identifying the publication in the public portal. please follow below link for the End User Agreement:

www.umlib.nl/taverne-license

Take down policy

If you believe that this document breaches copyright please contact us at:

repository@maastrichtuniversity.nl

providing details and we will investigate your claim.
}

Copyright and moral rights for the publications made accessible in the public portal are retained by the authors and/or other copyright owners and it is a condition of accessing publications that users recognise and abide by the legal requirements associated with these

- Users may download and print one copy of any publication from the public portal for the purpose of private study or research.

- You may not further distribute the material or use it for any profit-making activity or commercial gain

If the publication is distributed under the terms of Article 25fa of the Dutch Copyright Act, indicated by the "Taverne" license above, 


\title{
Development from childhood to adulthood increases morphological and functional inter-individual variability in the right superior temporal cortex
}

\author{
Milene Bonte ${ }^{\mathrm{a}, *}$, Martin A. Frost ${ }^{\mathrm{a}}$, Sanne Rutten ${ }^{\mathrm{a}}$, Anke Ley ${ }^{\mathrm{a}, \mathrm{b}}$, Elia Formisano ${ }^{\mathrm{a}, 1}$, Rainer Goebel ${ }^{\mathrm{a}, \mathrm{c}, 1}$ \\ a Department of Cognitive Neuroscience and Maastricht Brain Imaging Center, Faculty of Psychology and Neuroscience, Maastricht University, P.O. Box 616, 6200 MD, \\ Maastricht, The Netherlands \\ ${ }^{\mathrm{b}}$ Department of Medical Psychology and Neuropsychology, Tilburg University, Tilburg, The Netherlands \\ ${ }^{c}$ Netherlands Institute for Neuroscience, Institute of the Royal Netherlands Academy of Arts and Sciences (KNAW), Amsterdam, The Netherlands
}

\section{A R T I C L E I N F O}

\section{Article history:}

Accepted 3 July 2013

Available online 16 July 2013

\section{Keywords:}

Auditory cortex asymmetry

Development

(f)MRI

Individual differences

Voice perception

\begin{abstract}
A B S T R A C T
We study the developmental trajectory of morphology and function of the superior temporal cortex (STC) in children (8-9 years), adolescents (14-15 years) and young adults. We analyze cortical surface landmarks and functional MRI (fMRI) responses to voices, other natural categories and tones and examine how hemispheric asymmetry and inter-subject variability change across age. Our results show stable morphological asymmetries across age groups, including a larger left planum temporale and a deeper right superior temporal sulcus. fMRI analyses show that a rightward lateralization for voice-selective responses is present in all groups but decreases with age. Furthermore, STC responses to voices change from being less selective and more spatially diffuse in children to highly selective and focal in adults. Interestingly, the analysis of morphological landmarks reveals that inter-subject variability increases during development in the right - but not in the left - STC. Similarly, inter-subject variability of cortically-realigned functional responses to voices, other categories and tones increases with age in the right STC. Our findings reveal asymmetric developmental changes in brain regions crucial for auditory and voice perception. The age-related increase of inter-subject variability in right STC suggests that anatomy and function of this region are shaped by unique individual developmental experiences.
\end{abstract}

(c) 2013 Elsevier Inc. All rights reserved.

\section{Introduction}

The human superior temporal cortex is a relevant cortical site for many auditory and language functions. In the adult brain, its morphology is highly asymmetric between hemispheres and highly variable across individuals. It includes one of the most commonly observed anatomical asymmetries of the brain, i.e. a larger planum temporale (PT) in the left as compared to the right hemisphere, which has been often related to a left hemispheric specialization for language (Geschwind and Levitsky, 1968; but see Dorsaint-Pierre et al., 2006; Eckert et al., 2006). Albeit less well-known, an opposite asymmetry is consistently observed in the superior temporal sulcus (STS), whose depth is greater in the right when compared to the left hemisphere (Ochiai et al., 2004; Van Essen, 2005). Both PT and STS asymmetries are already present in infants (Dubois et al., 2010; Glasel et al., 2011; Hill et al., 2010a), suggesting an underlying genetic component.

\footnotetext{
* Corresponding author. Fax: + 31433884125 .

E-mail address: m.bonte@maastrichtuniversity.nl (M. Bonte).

1 These authors have equal contribution.
}

Characteristic functional asymmetries include enhanced left hemispheric responses to linguistic speech information in the posterior and/or anterior superior temporal cortex (Binder et al., 2000; Kilian-Hütten et al., 2011; Obleser et al., 2007; Scott et al., 2000) and enhanced right hemispheric responses to human voices, especially toward the anterior STS (Belin et al., 2000; Formisano et al., 2008; von Kriegstein et al., 2003). Interestingly, 3-month-old infants show a relatively strong left lateralization of the superior temporal activity to speech and speech-like sounds (Dehaene-Lambertz et al., 2002, 2010). Furthermore, by 3 to 7 months, infants show a strong lateralization of neural responses to voices as compared to non-vocal sounds in the right anterior STS (Blasi et al., 2011) or right posterior superior temporal cortex (Grossmann et al., 2010). Paralleling language development, the neural systems for speech perception continue to refine throughout childhood and adolescence (Bonte and Blomert, 2004; Parviainen et al., 2011). Less is known on the developmental trajectory of voice selective activity in the superior temporal cortex and its lateralization, which is a focus of the present study.

Morphologically, the superior temporal cortex shows interindividual variability in the number of transverse gyri of Heschl (HG), including incomplete and complete HG duplications in the left 
and/or right hemisphere (Campain and Minckler, 1976; Leonard et al., 1998). Other sources of inter-individual variability include the size and form of the planum temporale (Shapleske et al., 1999) and the folding pattern of the STS (Im et al., 2010; Ochiai et al., 2004). Inter-individual variability in morphology has been related to expertise in music (Schneider et al., 2002) and speech analysis (Golestani et al., 2011), and to language dysfunctions in dyslexia (Leonard et al., 2006) and schizophrenia (Shapleske et al., 1999). Surprisingly little is known about developmental changes in normal morphological variability. Studying these developmental changes can further our understanding of regionally specific maturation and learninginduced plasticity.

In the present study, we investigated structural and functional development of the superior temporal cortex by analyzing hemispheric asymmetry and inter-individual variability of cortical surface landmarks and fMRI responses to voices and control sounds in children, adolescents and young adults. We assessed morphological and functional asymmetries by calculating hemispheric differences in anatomical landmarks and fMRI activity in individual subjects and subsequently comparing them to their age group means. Furthermore, we examined morphological variability by projecting individual anatomical landmarks on a group surface for each age group and computing intersubject distances, and functional variability by calculating inter-subject overlap of fMRI responses after minimizing macro-anatomical differences by means of cortex-based group alignment (Frost and Goebel, 2012; Goebel et al., 2006).

\section{Materials and methods}

\section{Participants}

(f)MRI measurements were performed in thirty-seven healthy Dutch-speaking participants (13 children, 14 adolescents, 10 adults). Analysis was performed on 30 subjects: 10 children (8f, mean (SD) age $9.1 \pm 0.7$ years), 10 adolescents ( $8 \mathrm{f}$, mean age $14.1 \pm 0.6$ years) and 10 adults (6f, mean age $24.1 \pm 2.4$ years). Data of 3 children and 4 adolescents were discarded: 2 children did not complete the measurement, 1 child moved too much during the measurements, 3 adolescents showed no significant activation to tones and/or voices and 1 adolescent was discarded due to technical problems during the measurement. For the functional analysis 2 additional children had to be excluded due to excessive movement, resulting in the inclusion of 8 out of 10 children ( $6 f$, mean age $9.1 \pm 0.7$ years). Adults and adolescents received a monetary reward for participation ( $€ 5$ per hour), children could select a toy (e.g. car, ball, bracelet, book) after both sessions. Informed consent was obtained from all adult and adolescent participants and from parents of adolescents and children, according to the approval by the Ethical Committee of the Faculty of Psychology and Neuroscience at the University of Maastricht.

All participants were Dutch speakers with normal hearing as assessed with a pure tone audiogram (detection thresholds of frequencies from 250 to $8000 \mathrm{~Hz}$ at 0-20 dB). Each age group included 9 right-handed participants and 1 left-handed participant, as assessed by a handedness questionnaire adapted from Annett (1979). The adaptation consisted of replacing four less child oriented items (striking a match, using thread, using a broom, using a shovel) with child oriented items (drawing, using a spoon, using a hair comb, turning a page). All children, adolescents and adults showed normal language development and cognitive abilities as assessed by psychometric tests (see Table 1). Psychometric tests included a word reading task and a phoneme deletion task (Blomert and Vaessen, 2009), as well as the block design, similarities and digit span sub-tests of the WISC (Wechsler et al., 2000) or WAIS (Kort et al., 2005). ANOVA analyses were performed on age-appropriate t-scores (word reading, phoneme deletion; mean $=50 ; \quad S D=10$ ) or norm scores (WISC/WAIS subtests; mean $=10 ; \mathrm{SD}=3$ ). There were no significant age group differences,
Table 1

Psychometric test results across age groups.

\begin{tabular}{llll}
\hline & Child & Adolescent & Adult \\
\hline Word reading $^{\mathrm{a}}$ & $57.0(3.2)$ & $57.6(1.5)$ & $57.8(1.7)$ \\
Phoneme deletion $^{\mathrm{a}}$ & $51.0(10.8)$ & $61.0(3.9)$ & $59.4(7.5)$ \\
WISC/WAIS $^{\text {Similarities }}$ & & & \\
Block design $^{\mathrm{b}}$ & $10.4(3.0)$ & $12.3(3.3)$ & $13.3(2.8)$ \\
$\quad$ Digit span $^{\mathrm{b}}$ & $10.5(2.8)$ & $10.3(3.2)$ & $11.5(3.4)$ \\
\hline
\end{tabular}

a Age-appropriate t-scores, mean $=50, \mathrm{SD}=10$.

b Age-appropriate norm scores, mean $=10, \mathrm{SD}=3$.

with the exception of the phoneme deletion test. The latter test showed a main effect of age group $(F(2,27)=4.2 ; \mathrm{p}=0.026)$ and a post-hoc difference between children and adolescents $(p=0.012)$ and children and adults $(p=0.033$ ), but not between adolescents and adults $(\mathrm{p}=0.66)$. These differences were due to 3 children who performed just below the age-appropriate norm with t-scores of 34 , 37 and 38. Importantly however, their t-scores for word reading corresponded to 53, 60 and 58 and their average WISC norm scores corresponded to 11,9 and 10 respectively, indicating normal reading and cognitive abilities.

\section{Anatomical measurement}

Brain imaging was performed with a 3 Tesla scanner (head setup, Allegra - Siemens) at the Maastricht Brain Imaging Center. Children and adolescents were acquainted to the scanning environment and trained to minimize head movement using a simulation scanner. Movement training consisted of two 6-minute blocks during which children/adolescents watched a cartoon movie that was shortly interrupted whenever head movement would exceed $3 \mathrm{~mm}$. A high-resolution structural scan (voxel size, $1 \times 1 \times 1 \mathrm{~mm}^{3}$ ) was collected for each subject using a T1-weighted three-dimensional ADNI sequence [TR, 2050 ms; echo time (TE), 2.6 ms; 192 sagittal slices].

\section{Preprocessing and cortex based alignment}

Anatomical data were analyzed using BrainVoyager QX 2.4 (Brain Innovation). The anatomical images of each participant were normalized into Talairach space. This operation included the definition of the landmarks AC (anterior commissure) and PC (posterior commissure) as well as a demarcation of the extremities of the cortex (inferior, superior, left and right most points); the defined subject-specific landmarks were then used to rotate each brain in the AC-PC plane followed by piecewise, linear transformations to fit each brain in the common Talairach "proportional grid" system (Talairach and Tournoux, 1980). The achieved brain normalization aligns global orientation and adjusts size of the brains without distorting individual brain anatomy. Thus, it is suited for the analysis of morphological features such as sulcal depth or orientation of sulci. However, with Talairach (as well as the related template-based MNI) normalization, gyri and sulci are not aligned well across brains. For fine-grained questions requiring maximal correspondence between brain anatomical locations (e.g. to study functional variability with respect to morphology), more advanced cortex-based alignment schemes have been introduced (e.g. Fischl et al., 1999; Goebel et al., 2006). For advanced alignment of gyri and sulci as well as for visualization, mesh representations of the cortical surface were created using an automatic segmentation tool (Kriegeskorte and Goebel, 2001). Curvature maps, reflecting the gyral/sulcal folding pattern, were then derived from the extracted cortical meshes for both hemispheres of each individual. To allow mesh vertices to find corresponding locations across brains, each hemisphere was inflated to a spherical representation to create a restricted space for vertex displacements (e.g. Fischl et al., 1999). While this representation is void of original morphology, information about the gyral/sulcal folding 
pattern is retained on the spheres by overlaying the calculated individual curvature maps. These maps serve as goodness-of-fit measures during alignment since they allow quantifying the overlap of concave (sulci) and convex (gyri) regions. Cortex based alignment was then performed by first carrying out a rigid alignment to a spherical curvature map of a randomly chosen subject for each age group to minimize differences in rotation and orientation of the spherical surface reconstructions. This was followed by a non-linear morphing alignment to a dynamic group average curvature map using a coarse to fine (multi-scale) approach. During the early phase, smoothed curvature maps are used to align gross anatomical features (central sulcus, Sylvian fissure, STS, etc.). As the alignment algorithm progresses, more detailed curvature information is added to maximize macro-anatomical correspondence across the whole cortex (Frost and Goebel, 2012; Goebel et al., 2006). The employed coarse-to-fine scheme ensures that small local structures that may differ across brains (e.g. small gyri and notches) are placed in the same relative position in each brain, i.e. the alignment approach tolerates local curvature differences within established more global correspondence (e.g. large sulci and gyri). Cortex-based alignment results in an averaged folded group brain and creates tables that assign each vertex of an individual cortex mesh to the corresponding vertex of the created group mesh. The established vertex correspondence mapping was used to warp hemisphere meshes from individual (Talairach) subject space to the cortically aligned folded group space thereby creating improved co-registration of functional data and anatomical landmark definitions. To optimally align sulci and gyri and to avoid comparisons that are due to potential age-group mis-alignments related to global anatomical changes with age (Gogtay et al., 2004), cortex-based alignment was performed separately within each age group. In each age group, the alignment led to comparable and substantial reduction of anatomical variability for the STG, STS and FTS (see Fig. 1b). Due to the variability in HG morphology with complete posterior and common stem duplications in a substantial number of subjects (see Supplementary Fig. 1), the alignment of the HG was suboptimal in each of the three age groups and therefore HG was not included in the anatomical variability analysis. Importantly, in the right hemisphere, where we observed our main developmental effects, the number of HG duplications was stable across age groups.

\section{Definition of anatomical landmarks}

Five landmarks in the superior temporal cortex were manually labeled and their spatial variability was measured both before and after cortex-based alignment. The five landmarks are illustrated in Fig. 1a and consist of the superior temporal sulcus (STS), the superior temporal gyrus (STG), the first transverse sulcus (FTS), the Heschl's sulcus (HS) and the planum temporale (PT). The landmarks were identified and labeled on each individual subject's cortical mesh representation according to the following criteria (Frost and Goebel, 2012; Kim et al., 2000; Pantazis et al., 2010). (1) The superior temporal sulcus separates the superior from the middle temporal gyrus and was traced from its anterior border near the temporal pole until its posterior split into an ascending and descending (or horizontal) branch. STS trajectory was traced continuously along the depth of the sulcus and across discontinuities when they occurred (Ochiai et al., 2004; Ono et al., 1990), i.e. by tracing the shortest path between the two closest sulcal points prior to and after the discontinuity. (2) The superior temporal gyrus runs parallel to the lateral sulcus (Sylvian fissure) and the STS, and was traced from its anterior border at the temporal pole to its posterior border at the temporal parietal junction, until the STG ascends to the supramarginal gyrus. (3) The first transverse sulcus runs obliquely across the upper surface of the STG, and forms the anterior medial border of Heschl's gyrus (HG). FTS was traced from its origin near the retroinsular region, near the medial border of HG until its endpoint on the planum polare. (4) Heschl's sulcus forms the posterior limit of HG and was traced from the medial border of HG until its antero-lateral border on the superior temporal surface or at the lateral rim of the STG. (5) The planum temporale (PT) is a triangular region on the superior temporal surface posterior to HG (see purple region in Fig. 1a). Following Kim et al. (2000) its anterior-medial border was defined by the HS, or alternatively by the sulcus intermedius (SI) in case it was present. The SI is a

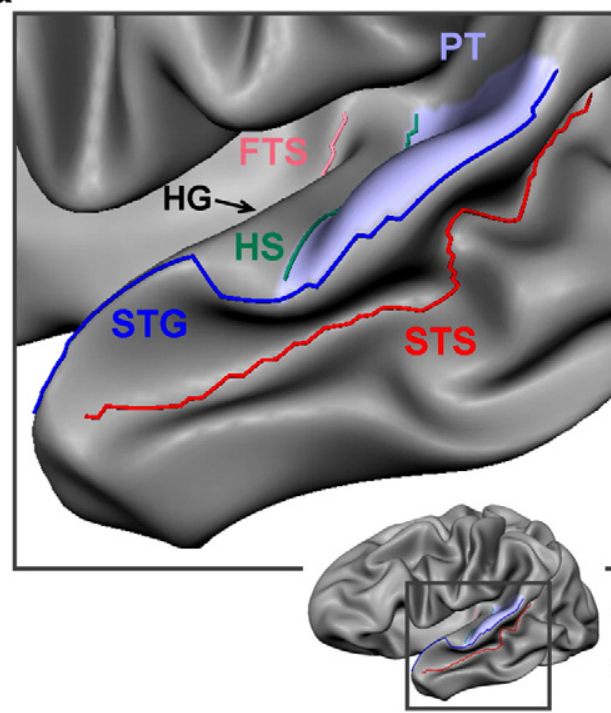

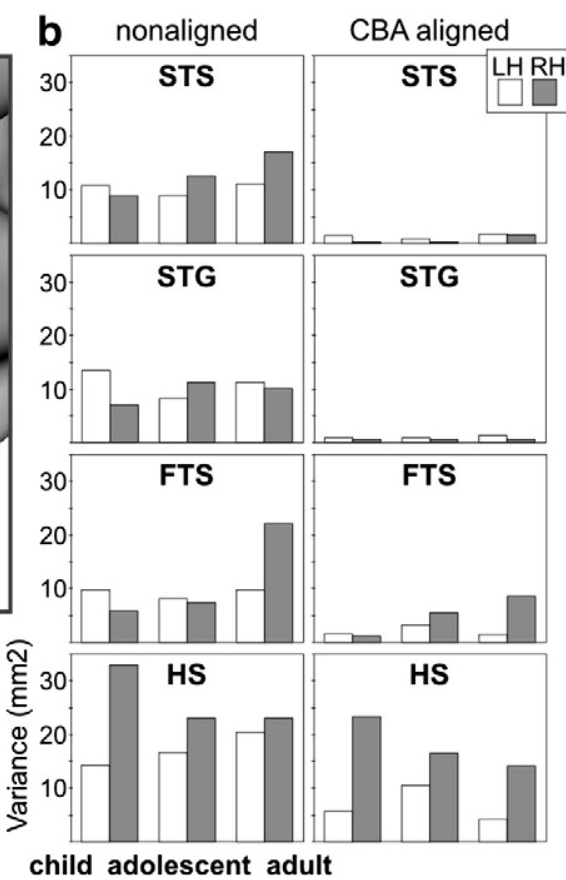

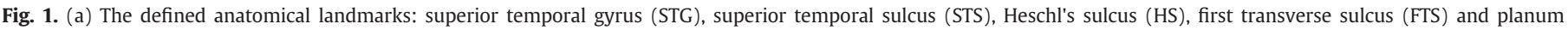

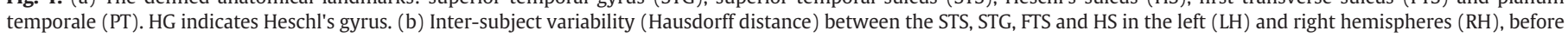
and after cortex-based alignment. 
defined as a sulcus on the crown of HG splitting the gyrus into two divisions that remain connected by a common medial stem (Kim et al., 2000; Leonard et al., 1998). Laterally the PT was confined by the lateral rim of the STG. The posterior border was traced from the medial origin of HS through the deepest point of the Sylvian fissure until the posterior point of the STG at the temporal parietal junction. We additionally determined the number of common stem duplications due to the presence of an SI as well as complete posterior HG duplications due to the presence of a second posterior HS, across hemispheres and age groups (see Supplementary Fig. 1).

\section{Quantification and statistical analysis}

Analysis of anatomical asymmetry focused on two measures for which hemispheric asymmetries have been reported in infants and adults: PT area size and STS sulcal depth (Dubois et al., 2010; Glasel et al., 2011; Hill et al., 2010a; Ochiai et al., 2004; Van Essen, 2005). In addition, we measured the length of the STS within the temporal cortex, from its anterior border at the temporal pole until its posterior split into an ascending and descending branch. PT area size was measured on each individual subject's folded cortical mesh representation by building the sum of the area of all mesh triangles enclosed by the three specified anatomical landmarks (see above). STS length was determined in terms of (1) Euclidean distance (Ochiai et al., 2004), i.e. distance between the most anterior and most posterior points, and (2) trajectory distance, i.e. the sum of vertex-vertex distances along the STS including local and global folding patterns. Because all brains were normalized to the Talairach template, differences in size of brains between age groups were removed allowing comparison of the degree of lateralisation to be made. PT area and STS length measures were tested using mixed-design ANOVAs with hemisphere as within subject factor and age group as between subjects factor.

STS sulcal depth values were sampled for each vertex of an individual subject's folded cortical mesh representation from a sulcal depth volume map measuring the shortest distance of each voxel of a white/gray matter segmentation to the brain surface. To obtain the surface of the brain, the sulci of the segmented brain were filled by a morphological closing operation. The shortest distance was then calculated using a chamfer distance transform operation starting at the obtained brain surface boundary. This results in a volume map with distance values at each voxel in the space between the white/ gray matter boundary and the brain surface boundary (i.e. within the sulci) indicating the distance of a voxel to the brain surface. In order to carry the distance values from volume space to the subject's mesh surface, the distance values were sampled at the coordinates of the vertices of the folded mesh representation. In order to obtain normalized and aligned sulcal depth values across subjects, for each age group the left and right STS were traced on the group aligned cortical mesh, according to the criteria described above, and aligned to each individual subject's cortical mesh using individual transformation parameters obtained during cortex based alignment. Statistical significance of inter-hemispheric differences in STS sulcal depth was assessed with a mixed-design ANOVA with hemisphere and segment (anterior, middle, posterior) as within subjects factors and age group as between subjects factor.

Inter-individual variability of sulcal and gyral landmarks was quantified in terms of the variability of their trajectories. Following Pantazis et al. (2010), we used a modified Hausdorff distance that quantifies the pair-wise between subjects differences of the trajectories and enables estimating the group variance (for exact definition, see Pantazis et al. (2010)). Since the variance is calculated around 0, a small (near 0) variance value indicates that trajectories are perfectly aligned. Given 10 subjects per age group, trajectory distances are estimated based on 45 unique pairs per landmark (i.e. n-pairs $=n^{*}(n-1) / 2$ ). In each age group and for each of the landmarks, FTS, HS, STG and STS, we analyzed (1) an overall distance measure that gives the variance of the 45 pair-wise Hausdorff distances between the sulcal/gyral trajectories of all subjects, and (2) the separate 45 pair-wise Hausdorff distances of the sulcal/gyral trajectories. Because distance measures of HS were highly variable (see Fig. 1b) and dependent on the presence of an SI in part of the subjects (see Supplementary Fig. 1), they were not included in the analysis. The 45 pair-wise STS, STG and FTS distance measures were tested using mixed-design ANOVAs with hemisphere as within subject factor, age group as between subjects factor and subject-pairs as covariates. In case of significant hemisphere by age group interactions, we performed post-hoc ANOVAs separately for each hemisphere, with age group as between subjects factor and subject-pairs as covariates. Inter-individual variability of the PT, an area of cortical surface that cannot be described as a path (gyrus or sulcus), was quantified using the following vertex-wise measure of overlap:

$\mathrm{o}_{\mathrm{v}}=\mathrm{N}_{\mathrm{v}} / \mathrm{N}$

where $N_{v}$ is the number of subjects whose planum temporale occupies a certain vertex and $\mathrm{N}$ is the number of subjects.

\section{Functional MRI measurement}

For each subject, an 8-minute functional run $(3 \mathrm{~mm} \times 3 \mathrm{~mm} \times$ $3 \mathrm{~mm}$ ) was collected using a standard echoplanar-imaging (EPI) sequence (repetition time $[\mathrm{TR}]=3.0 \mathrm{~s}$; acquisition time $[\mathrm{TA}]=2.0 \mathrm{~s}$, field of view $[\mathrm{FOV}]=192 \mathrm{~mm} \times 192 \mathrm{~mm}$, matrix size $=64 \times 64$, echo time $[\mathrm{TE}]=32 \mathrm{~ms}$ ). Each volume consisted of 33 slices (distance factor 10\%), including the temporal cortex. During the measurements, subjects listened to auditory stimuli that were presented binaurally and at a comfortable listening level via MR compatible headphones in the 1000 -ms silent gap between two volume acquisitions. The functional run consisted of 12 stimulation blocks ( $18 \mathrm{~s} / 6$ volumes) alternated with $12 \mathrm{~s}$ (4 volumes) rest. During the stimulation blocks, participants listened to either (1) vocal sounds (7 non-speech sounds and 5 meaningless speech sounds), (2) other natural categories (musical instruments and environmental and animal sounds), both adapted from Belin et al. (2000), or (3) tones (amplitude modulated ( $8 \mathrm{~Hz}$ ) tones ranging from 0.3 to $3 \mathrm{kHz}$ ).

\section{Preprocessing of fMRI activity}

fMRI data were subjected to conventional pre-processing in BrainVoyager QX 2.4, including slice scan-time correction (using sinc interpolation), high-pass temporal filtering to remove nonlinear drifts of five or less cycles per time course, and 3-dimensional motion correction (Goebel et al., 2006). Functional data were spatially smoothed to $4 \mathrm{~mm} \times 4 \mathrm{~mm} \times 4 \mathrm{~mm}$. All participants included in the analysis minimized movements to maximally $2 \mathrm{~mm}$ in any direction. To minimize the possible effects of these small movements, each subject's motion correction parameters were included as confound predictors in our general linear model (GLM) analysis that was performed on time course data sampled on individual cortex meshes. Because fMRI data were acquired using a block-design, a single predictor per stimulus block was convolved with a double gamma hemodynamic response function (HRF). The resulting number of active voxels was very similar across groups, indicating that this standard HRF model provided a comparable and good fit of blood oxygen level dependent (BOLD) responses in each age group (see Supplementary Table 1 ). In order to map fMRI signal time courses from volume space to surface space, values located between the gray/ white matter boundary and up to $4 \mathrm{~mm}$ into gray matter toward the pial surface were sampled with trilinear interpolation and averaged, resulting in a single value for each vertex of a cortex mesh. Note that throughout the paper, we still refer to functionally active voxels instead of vertices, because this is the most commonly used term in fMRI literature. Importantly, GLM analysis was performed after macro- 
anatomical variability had been minimized using cortex-based alignment for each age group. In each age group, the alignment was able to greatly reduce anatomical variability for the STG, STS and FTS but less so for the HS, due to the presence of an SI in part of the subjects (see Fig. 1b).

\section{Quantification and statistical analysis}

Functional analysis focused on the superior temporal activity for the following four contrasts: (1) voice selectivity (voices $>$ (other categories + tones)/2), (2) voices $>$ silent baseline, (3) other categories $>$ silent baseline and (4) tones $>$ silent baseline. To examine the inter-individual variability of the fMRI responses relative to the cortex-based aligned group anatomy we constructed probabilistic maps (Frost and Goebel, 2012) for each functional contrast and for each age group. Probabilistic maps were obtained from individual subject's activation maps at a fixed statistical threshold (voice selectivity: $\mathrm{t}=1.96, \mathrm{p}=0.05$; single condition contrasts: $\mathrm{t}=3.0$, $\mathrm{p}=0.003$ ) and at a fixed cluster threshold of $25 \mathrm{~mm}^{2}$. The resulting group maps show regions of 50 to $100 \%$ subject overlap (i.e. $\mathrm{n}=4$ to $\mathrm{n}=8$ in children and $\mathrm{n}=5$ to $\mathrm{n}=10$ in adolescents and adults) at a fixed group cluster threshold of $20 \mathrm{~mm}^{2}$. See Supplementary Fig. 2 for corresponding random effects group-specific GLM maps. We did not perform overall random effects GLM analyses involving all groups together as that would require the alignment of the cortices across age groups, which may be problematic due to global anatomical changes with age (Gogtay et al., 2004). Instead, we quantified group differences through the comparisons of measures of hemispheric asymmetry and inter-individual variability calculated separately for each group. These analyses were restricted to the left and right temporal cortices by applying the same average anatomical masks across the three age groups (see Supplementary Fig. 3). The anatomical masks included the superior temporal plane, STG and STS and comprised all superior temporal activity to voices, other natural categories and tones. The left and right hemisphere masks were constructed such that they contained equal numbers of vertices. Hemispheric asymmetry was quantified by calculating individual $\mathrm{RH}-\mathrm{LH}$ differences in the number of active voxels and comparing their group means across ages. This was done for each of the four functional contrasts at a large range of $\mathrm{t}$-thresholds $(\mathrm{t}=0.0$ to $\mathrm{t}=7.0)$. Independent-sample t-tests were used to compute statistical significance of age group differences in laterality. Inter-individual variability was quantified by calculating the number of commonly active voxels for different levels of subject overlap ( $\mathrm{n}=4$ to $\mathrm{n}=8$ ) at a large range of t-thresholds $(t=0.0$ to $t=7.0)$. For adults and adolescents this analysis was based on the average of 100 random selections of 8 out of 10 subjects. Statistical significance of age group differences in variability was computed based on empirical null distributions determined by permuting subject labels across age groups (1000 iterations).

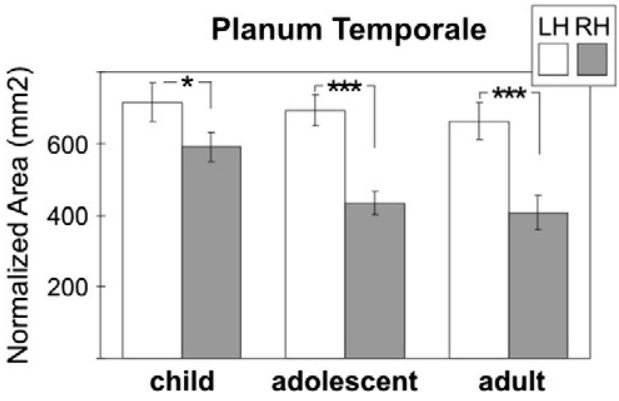

Fig. 2. Hemispheric asymmetry of the planum temporale (PT). Bar graph depicting normalized size (Talairach space) of the PT in the left ( $\mathrm{LH})$ and right (RH) hemispheres across the three age groups. ${ }^{*} \mathrm{p}<0.05,{ }^{* * *} \mathrm{p}<0.001$.

\section{Results}

Anatomical asymmetry: planum temporale and superior temporal sulcus

PT size was measured on each subject's folded cortical mesh representation. As expected, all age groups showed a larger PT in the left as compared to the right hemisphere (Fig. 2), leading to a main effect of hemisphere $(F(1,27)=58.6, p=0.000)$. Expressed in an asymmetry index $(\mathrm{R}-\mathrm{L}) /(\mathrm{R}+\mathrm{L})$ the larger left PT resulted in a value of -0.09 in children, -0.23 in adolescents and -0.24 in adults. Despite a trend toward smaller indices in children, results did not lead to a significant hemisphere-by-group interaction $(F(2,27)=$ 2.5, n.s.).

Each of the age groups additionally showed a rightward STS asymmetry with a deeper STS in the right as compared to the left hemisphere posterior to the HG/HS (Fig. 3). For statistical comparison of
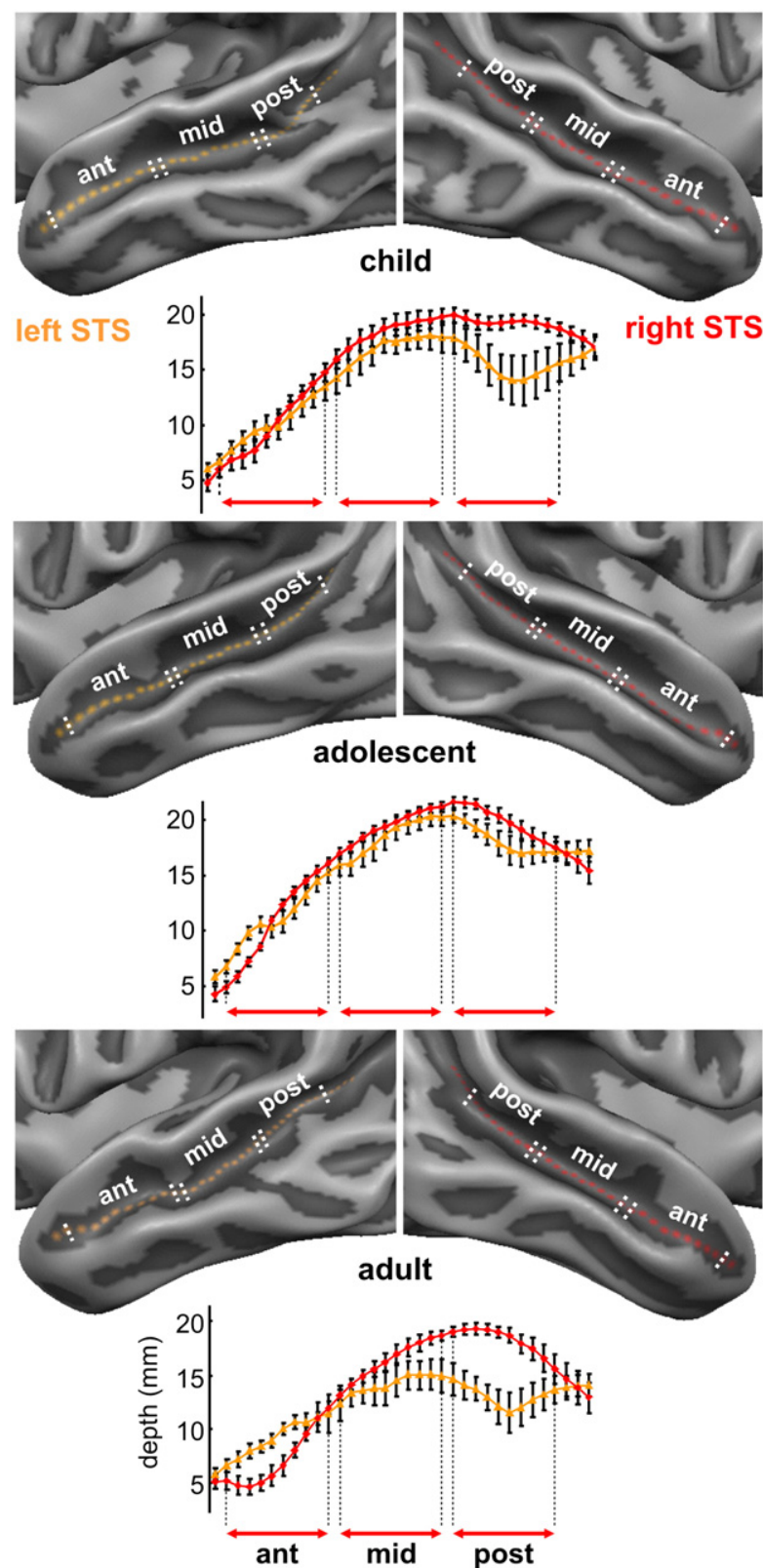

Fig. 3. Hemispheric asymmetry of the superior temporal sulcus (STS). Mean (SE) normalized sulcal depth ( $\mathrm{mm}$ ) along the left and right STS. For each age group, the average left and right hemisphere STS is projected on inflated group-average representations of the temporal cortex (light gray: gyri and dark gray: sulci) obtained after alignment of the cortices of the 10 subjects in each age group. 
Table 2

Mean (SE) normalized STS length (in mm) across age groups.

\begin{tabular}{lllrl}
\hline & LH Euclidean & RH Euclidean & LH trajectory & RH trajectory \\
\hline Child & $64(1.5)$ & $63(1.7)$ & $101(4.7)$ & $86(3.6)$ \\
Adolescent & $61(2.1)$ & $62(1.6)$ & $94(4.8)$ & $82(2.4)$ \\
Adult & $65(1.1)$ & $62(1.3)$ & $101(5.1)$ & $86(4.2)$ \\
\hline
\end{tabular}

hemisphere and age group effects along the posterior to anterior direction, in each age group and hemisphere, the STS was equally divided in anterior, middle and posterior sections. Results showed the main effects of hemisphere $(F(1,27)=12.0, p=0.002)$ and segment $(F(1,54)=163.4, \quad p=0.000)$ and a hemisphere-bysegment interaction $(F(2,54)=17.2, p=0.000)$. Separate tests per segment showed the main effects of hemisphere for the middle $(\mathrm{F}(1,27)=8.1, \mathrm{p}=0.008)$ and posterior $(\mathrm{F}(1,27)=22.2, \mathrm{p}=$ $0.000)$, but not for the anterior $(F(1,27)=3.2$, n.s. $)$ segment, and no significant hemisphere-by-group interactions. Inspection of individual depth profiles indicated a more prominent occurrence of sulcal bridges in the left as compared to right STS posterior to HG/HS (see also Ochiai et al., 2004), leading to a larger inter-individual variability of the depth profile of the posterior segment of the left as compared to the right STS in each of the three age groups (see standard errors in Fig. 3).
Furthermore, the presence of relatively prominent sulcal folding patterns in the left as compared to the right hemisphere is also consistent with our measures of STS length (Table 2). That is, STS length was significantly longer in the left as compared to the right hemisphere when measured in terms of STS trajectory, i.e. the sum of vertex-vertex distances along the STS including local and global folding patterns (main effect of hemisphere: $(\mathrm{F}(1,27)=25.0 ; \mathrm{p}=$ $0.000)$, hemisphere-by-group interaction $(F(2,27)=0.14$; n.s. $)$ ). However, results showed no asymmetry in STS length when measured in terms of Euclidean distance, i.e. the distance between the most anterior and the most posterior point independently of the sulcal trajectory (main effect of hemisphere $(F(1,27)=0.79$; n.s.), hemisphere-by-group interaction $(\mathrm{F}(2,27)=0.97$; n.s. $)$.

Anatomical variability: planum temporale and sulcal/gyral landmarks

Variability of the PT was estimated by determining interindividual overlap of the PT on cortical group mesh representations for each age group (Fig. 4a). The resulting measures of PT overlap suggest an age related increase in PT variability (decrease in overlap) in the right, but not in the left, hemisphere (Fig. 4b).

Variability of the STS, STG and FTS was tested based on the means of the pair-wise inter-subject distances per age group (Fig. 5; for a
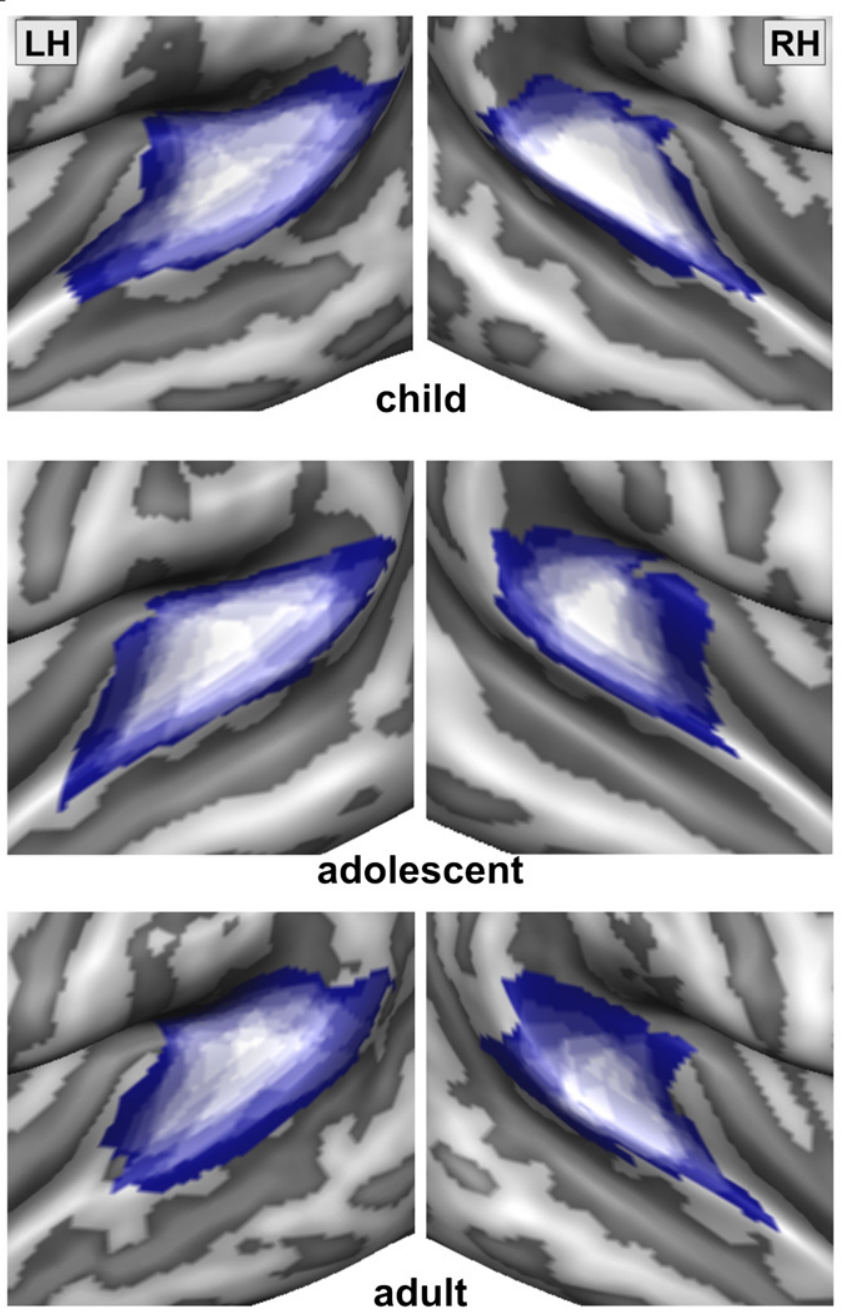
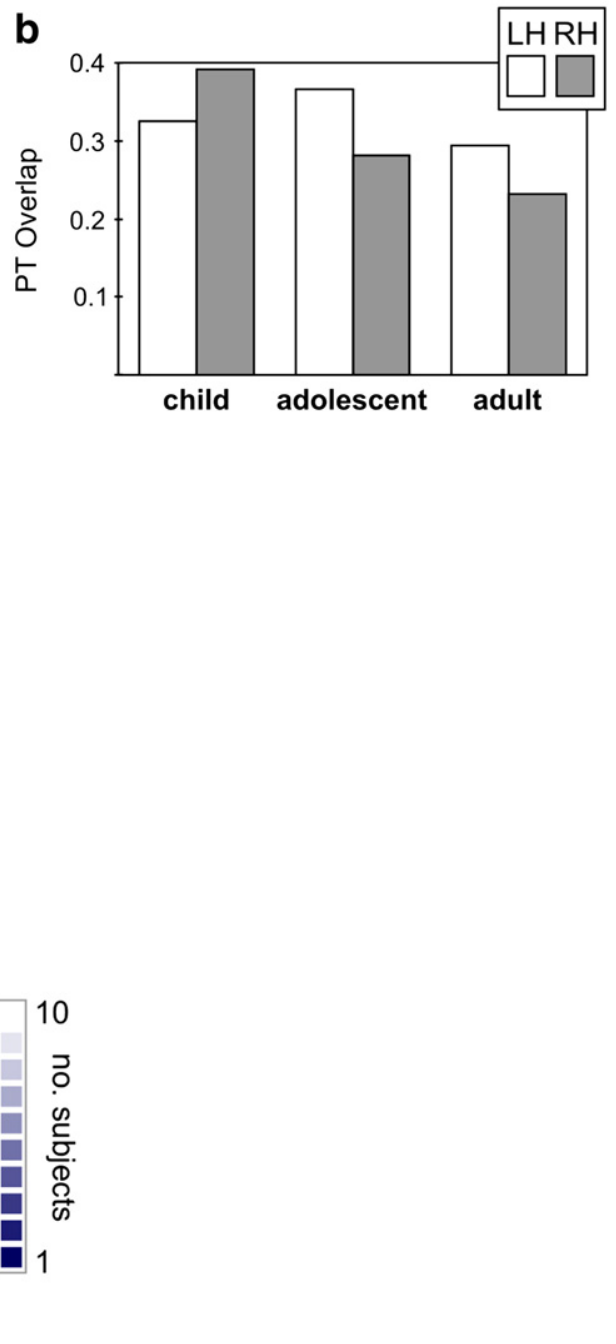

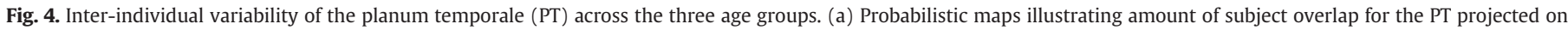

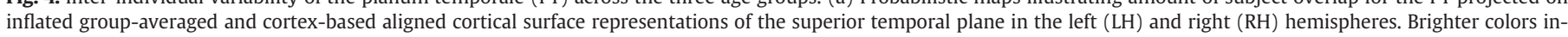
dicate larger inter-subject overlap (b) Bar graph depicting mean overlap of the left and right PT. 
a
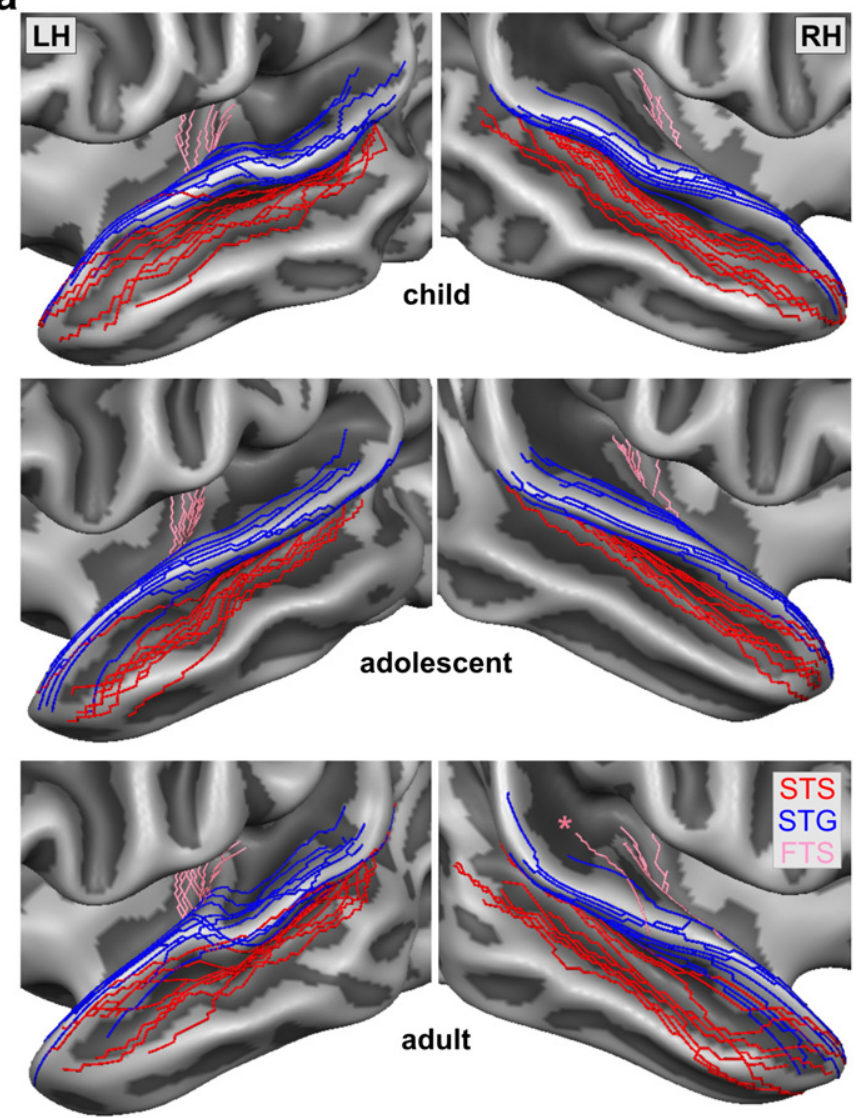

b
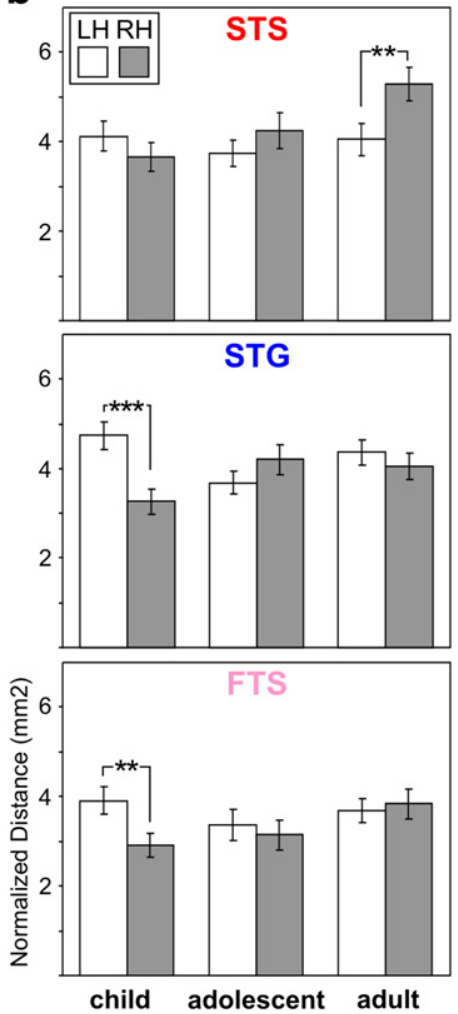

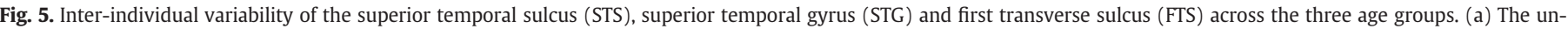

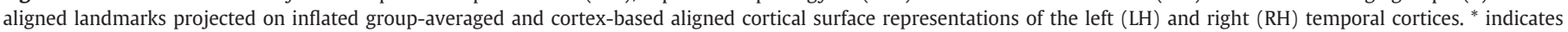

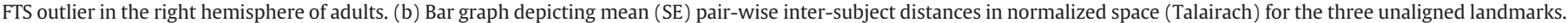
The right FTS outlier is not included in the bar graph of the adults. ${ }^{*} \mathrm{p}<0.05,{ }^{* *} \mathrm{p}<0.01,{ }^{* * *} \mathrm{p}<0.001$.

corresponding Hausdorff distances see Fig. 1b). Because the right hemisphere FTS of one of the adults clearly deviated from all others (see Fig. 5a), this subject was excluded for statistical analysis of the FTS. First, in adults, STS variability was significantly larger in the right as compared to the left hemisphere (main effect of hemisphere $F(1,130)=12.7$, $\mathrm{p}=0.000$; hemisphere-by-group interaction $\mathrm{F}(2,130)=4.2, \mathrm{p}=$ 0.018 ; post-hoc t-test adults $\mathrm{p}=0.005)$. Second, in children, STG variability was significantly larger in the left as compared to right hemisphere (hemisphere-by-group interaction $\mathrm{F}(2,130)=8.7, \mathrm{p}=0.000$; post-hoc t-test children $\mathrm{p}=0.000$ ). And third, in children, FTS variability was significantly larger in the left than in the right hemisphere (hemisphere-by-group interaction $\mathrm{F}(2,121)=3.2, \mathrm{p}=0.046$; posthoc t-test children $\mathrm{p}=0.001$ ).

Following the significant hemisphere-by-group interactions, we performed post-hoc ANOVAs to test for age group effects separately per hemisphere. Like the PT, the STS showed a developmental increase in inter-subject variability in the right hemisphere (STS: $F(2,130)=$ $5.6, \mathrm{p}=0.005$ ), together with stable variability in the left hemisphere (no significant age group effect). In contrast, the STG showed a significant age group effect in the left hemisphere $(F(2,130)=3.7, p=$ 0.034 ), due to a relatively high variability in children but no linear decrease with age, together with stable variability in the right hemisphere. No significant age group effects were found for the FTS.

\section{Functional activity in the superior temporal cortex}

In each age group, voices, other natural categories and tones evoked strong overlapping activation in the superior temporal cortex encompassing middle to posterior STG, planum temporale and HG. In addition to these areas, voices elicited enhanced activity bilaterally along the STG and extending into the STS, especially in the right hemisphere (see random effects GLM maps in Supplementary Fig. 2). This enhanced activation is also reflected in the voice selectivity contrast (first row in Supplementary Fig. 2), which is examined in detail below. Note that for each of the single-condition contrasts the number of active voxels was very similar across age groups indicating comparable data quality. Further analyses confirmed that there was no significant group difference in the average number of active ( $p<0.001$ ) voxels, as selected at single subject level (see Supplementary Table 1 , all pair-wise group comparisons $\mathrm{p}>0.19$ ).

To assess the spatial consistency/variability of responses across subjects, we examined probabilistic maps corresponding to the four functional contrasts (Fig. 6). Similar to the random effects GLM maps, probabilistic maps indicated a common overall activation pattern across groups. Interestingly, visual inspection of hemispheric differences indicated that a rightward asymmetry of spatial overlap of voice selective responses decreases with age. That is, in children, probabilistic maps show a small focus of overlapping responses in the left mid-STG near the lateral HG/HS, and increased overlap extending along the posterior to anterior STG and posterior to middle STS in the right hemisphere. Although a rightward asymmetry of voice selective overlap can also be observed in the other age groups, at this tthreshold, lateralization appears much less pronounced, especially in adults. Probabilistic maps of the three single condition contrasts indicate relatively strong overlap of right hemispheric responses in children, especially for voices. A leftward bias seems instead to be present for responses to other natural categories in adults. Furthermore, whereas children show relatively strong response overlap for each of 
child
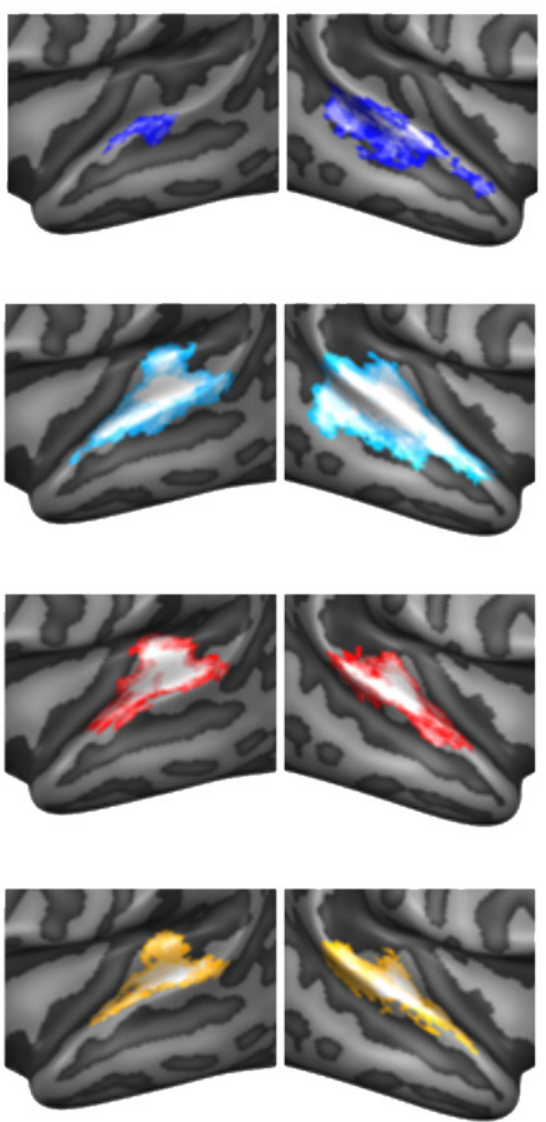

adolescent

voice selectivity

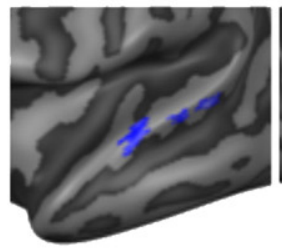

voices > baseline
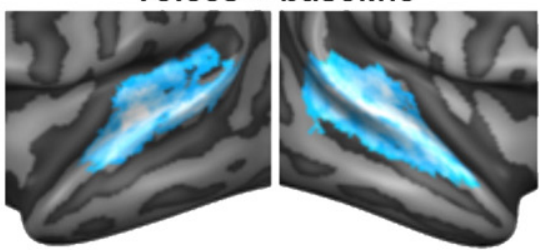

other $>$ baseline
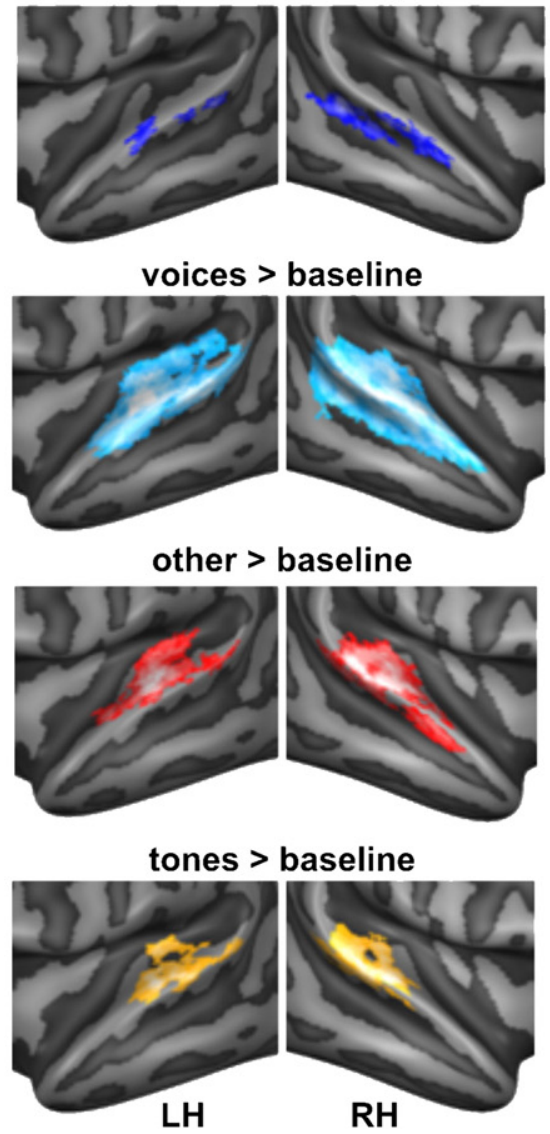
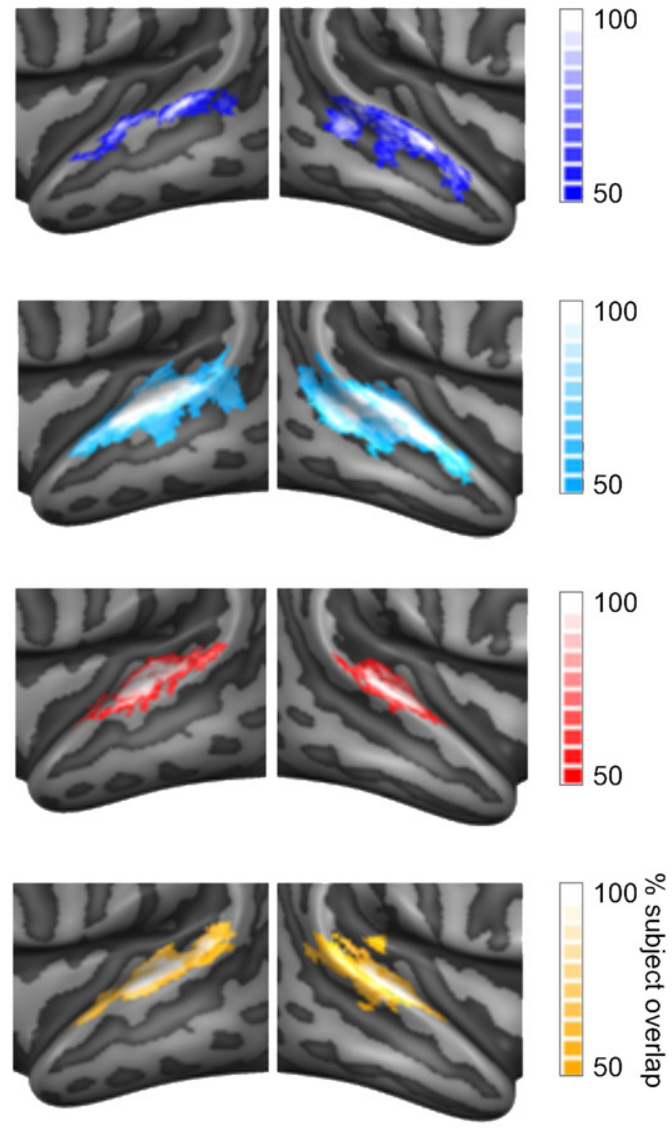

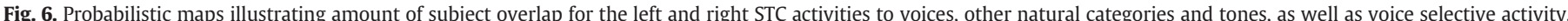

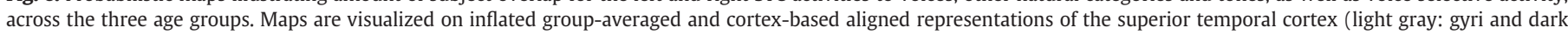

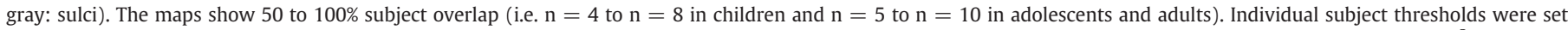

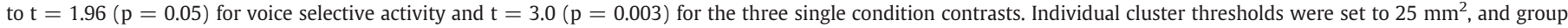
cluster thresholds were set to $20 \mathrm{~mm}^{2}$.

the single condition comparisons, in adults the area of response overlap for other categories and tones appears relatively small when compared to that of voices. To confirm these observations of group differences in probabilistic maps, we performed further analyses to assess statistically asymmetry and variability of functional responses.

\section{Functional asymmetry}

We quantified developmental changes in hemispheric lateralization by calculating individual right-left differences in the number of active voxels in the superior temporal cortex and comparing their means across age groups (Fig. 7). The resulting lateralization profiles confirm a right lateralization of voice selective responses in each of the age groups, together with a significantly enhanced right lateralization in children as compared to adults. Although adolescents' response profiles were intermediate between children and adults, the between group differences with adolescents did not reach significance. Profiles of single condition voice responses show an even greater developmental change in lateralization, with a strong rightward bias in children, a weaker bias in adolescents, and no apparent lateralization in adults. A similar effect was not observed for the other two single condition contrasts. Instead, responses to other categories, and to a lesser extent also responses to tones, show a leftward bias in adults but not in the other age groups.
By quantifying lateralization across a large range of t-tests, the profiles additionally revealed a developmental increase in the selectivity of the rightward asymmetry for voices. That is, in children and adolescents, lateralization profiles of voice selective responses peaked at relatively low $t$-thresholds (around $t=1.96, p=0.05$, blue and red arrows in Fig. 7) whereas in adults they peaked at a higher $\mathrm{t}$-threshold ( $\mathrm{t}=3.2, \mathrm{p}=0.002$, green arrow in Fig. 7 ). This age difference in selectivity also led to a significant difference between adults and adolescents at higher t-values where adolescents do not, but adults do show a right lateralization. Similar effects were not observed for the single condition contrasts. Together, these results demonstrate that a rightward asymmetry of voice selectivity is present in all age groups, but changes from being less selective (peaking at lower t-values) and more diffuse (larger number of voxels) in children toward more selective (peaking at higher t-values) and clustered (smaller number of voxels) in adults.

\section{Functional variability}

We quantified developmental changes in functional variability by calculating inter-subject overlap (number of commonly activated voxels) in the left and right superior temporal cortices and testing pair-wise age group differences. Fig. 8 illustrates these pair-wise group differences for different levels of subject overlap (horizontal axis: 50 to $100 \%$ overlap), and a large range of t-values (vertical 


\section{child adolescent adult}

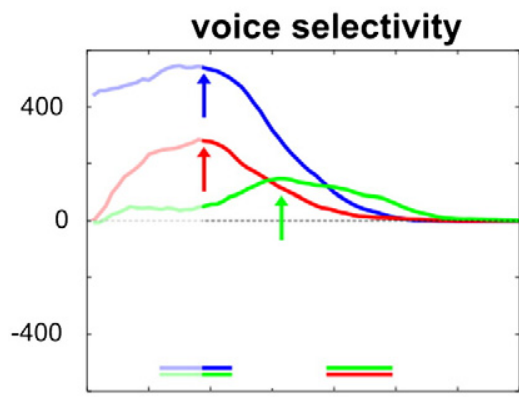

other $>$ baseline

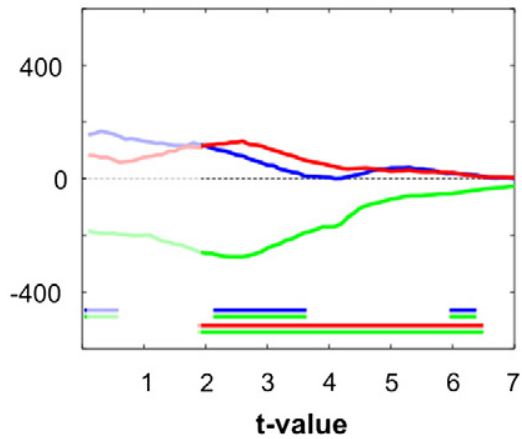

voices $>$ baseline

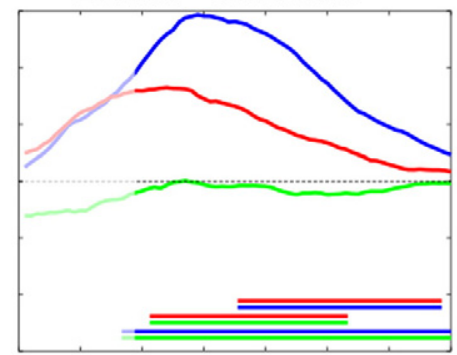

tones $>$ baseline

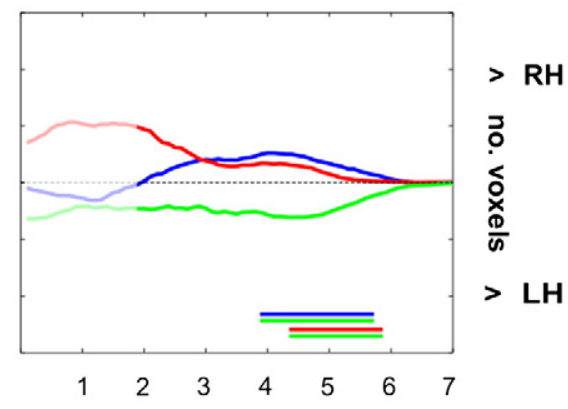

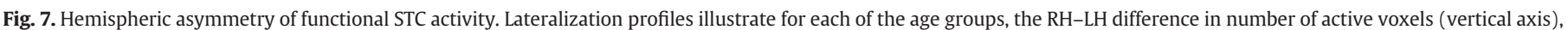

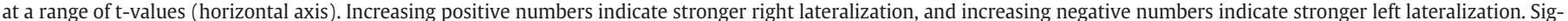

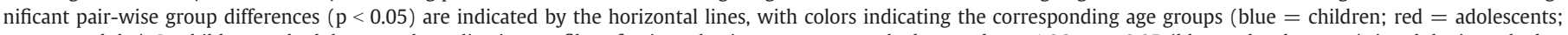

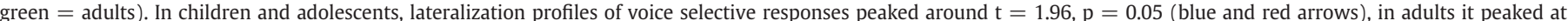

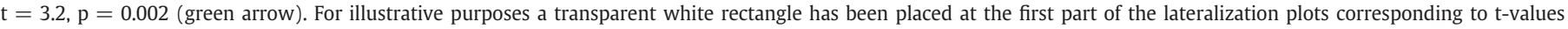
lower than $\mathrm{t}=1.96(\mathrm{p}<0.05)$.

axis: $\mathrm{t}=0.0$ to $\mathrm{t}=7.0$ ). The plots are masked for statistical significance, non-masked (bright) colors correspond to significant group differences ( $\mathrm{p}<0.05$ based on permutation of subject labels). Red colors indicate larger activity overlap in the younger age group, and blue colors indicate larger activity overlap in the older age group of the respective pair-wise comparisons. As can be seen in Fig. 8, voice selective responses did not yield statistically significant group differences, suggesting a relatively stable inter-individual variability in this age range. The analysis of single condition contrasts instead showed a significantly larger response overlap in the right superior temporal activity to voices, other categories and tones in children as compared to both adolescents and adults. In the left hemisphere, only responses to other categories showed greater overlap in children, whereas tone responses showed greater overlap in adults. Most importantly, these findings show that the observed developmental increase in the right hemispheric anatomical variability (STS, PT) also extends
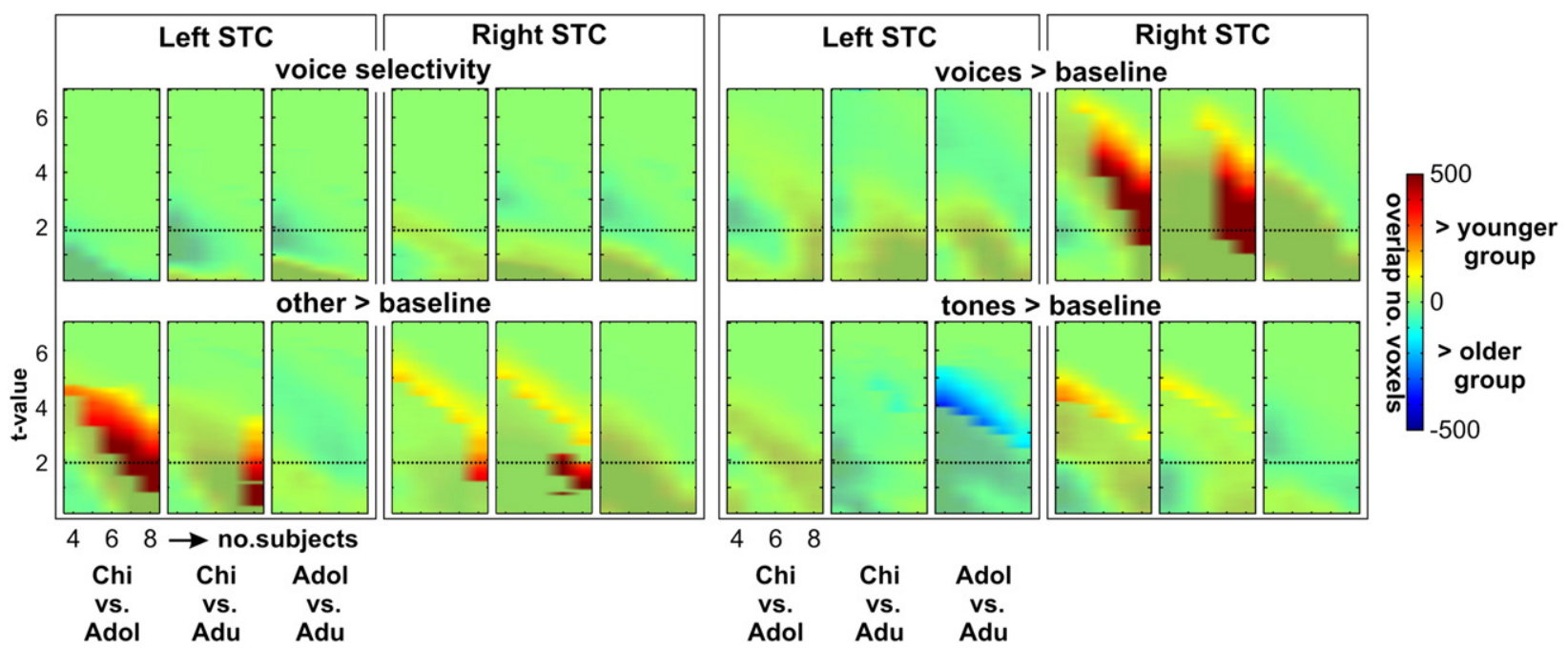

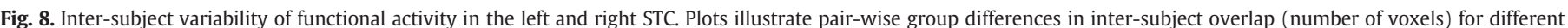

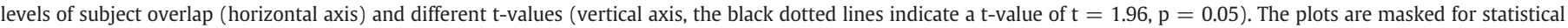

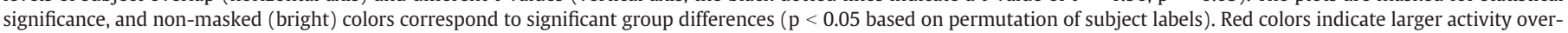
lap in the younger age group, and blue colors indicate larger activity overlap in the older age group of the respective pair-wise comparisons. 
to anatomically aligned functional activity across the superior temporal cortex.

\section{Discussion}

We investigated structural and functional development of superior temporal cortex in children, adolescents and adults by analyzing hemispheric asymmetry and inter-individual variability of anatomical landmarks and fMRI responses to voices, other natural categories and tones. By applying advanced analysis tools to individually determined markers we were able to highlight the unique developmental trajectory of the right superior temporal cortex. Results of the anatomical and functional measures are summarized in Tables 3 and 4 and discussed below.

A first aim of this study was to delineate developmental changes in known anatomical and functional asymmetries of the superior temporal cortex. The stable leftward asymmetry of PT surface area and rightward asymmetry of STS sulcal depth across age groups extend previous reports in adults (Ochiai et al., 2004; Van Essen, 2005) and infants (Dubois et al., 2010; Glasel et al., 2011; Hill et al., 2010a). Inspection of individual depth profiles and standard errors in Fig. 3 further suggests an asymmetry in terms of an increased variability of sulcal depth in the left as compared to right STS posterior to $\mathrm{HG} / \mathrm{HS}$ in all age groups. This increased variability most likely relates to a more prominent occurrence of sulcal bridges in this region as compared to its right hemisphere equivalent (Ochiai et al., 2004) and led to the age-independent leftward asymmetry of STS length when measured in terms of STS trajectory (Table 2). Although our findings suggest stable PT size, STS depth and STS length asymmetries throughout childhood and adolescence, superior temporal asymmetries may undergo other changes during this age period including for example a developmental increase in the hemispheric asymmetry of the Sylvian fissure slope (Sowel et al., 2002).

fMRI responses to voices, as compared to other categories and tones, showed the expected functional asymmetry of enhanced activity along the right STG/STS in adults (Belin et al., 2000) as well as in adolescents and children. Most interestingly, our results reveal a decrease in this rightward asymmetry from childhood to adulthood. This is in agreement with previous findings showing a strong right lateralization of brain responses to voices in infants (Blasi et al., 2011; Grossmann et al., 2010). More specifically, our results indicate that the rightward asymmetry for voices develops from being less selective (lower t-values) and more diffuse (larger number of voxels) in children toward highly selective and focal activation spots in adults. When adults acquire complex new skills brain activity initially spreads over a diffuse network of brain areas. Performance improvements with learning are paralleled by a shift toward more focal activation in cortical areas relevant for the trained task (Karni et al., 1998). Previous fMRI findings in 9 to 12 year old children suggest that developmental improvements in performance of complex

Table 3

Hemispheric asymmetry: age effects.

\begin{tabular}{|c|c|c|}
\hline & Asymmetry & Age effect \\
\hline \multicolumn{3}{|l|}{ Anatomy } \\
\hline PT area size & $\mathrm{LH}>\mathrm{RH}$ & No \\
\hline STS depth & $\mathrm{RH}>\mathrm{LH}$ & No \\
\hline \multicolumn{3}{|l|}{ Function } \\
\hline Voice selective & $\mathrm{RH}>\mathrm{LH}$ & $\begin{array}{l}\text { Decrease with age } \\
\text { Child vs. adult }\end{array}$ \\
\hline Voice $>$ baseline & $\mathrm{RH}>\mathrm{LH}$ & $\begin{array}{l}\text { Decrease with age } \\
\text { Child vs. adolescent vs. adult }\end{array}$ \\
\hline Other $>$ baseline & $\mathrm{LH}>\mathrm{RH}$ & Only in adults \\
\hline Tones $>$ baseline & $\mathrm{LH}>=\mathrm{RH}$ & Only in adults \\
\hline
\end{tabular}

Table 4

Inter-subject variability: age effects in the left $(\mathrm{LH})$ and right $(\mathrm{RH})$ hemispheres.

\begin{tabular}{lll}
\hline & Age effect LH & Age effect RH \\
\hline $\begin{array}{l}\text { Anatomy } \\
\text { PT }\end{array}$ & No & \\
STS & No & Increase with age \\
STG & Decrease with age & Increase with age \\
FTS & No & No \\
Function & & \\
Voice selective & No & \\
Voice $>$ baseline & No & No \\
& & Increase with age \\
Other $>$ baseline & Increase with age & Child vs. adolescent/adult \\
& Child vs. adolescent/adult & Increase with age \\
Tones $>$ baseline & Decrease with age & Child vs. adolescent/adult \\
& Child/adolescent vs. adult & Child vs. adolescent/adult \\
\hline
\end{tabular}

cognitive tasks are reflected by a similar shift from diffuse to focal activity in frontal cortex (Durston et al., 2006). The present findings extend this framework to the domain of auditory perception, and in particular to the perception of human voices. We would predict that improvements in the behavioral efficiency of voice recognition with age and/or learning would lead to this shift from more diffuse to more segregated (focal) activity in the superior temporal cortex. Furthermore, this refinement of voice selectivity parallels developmental changes in face selective responses of the right fusiform face area across the same age groups (Golarai et al., 2007, 2010). When compared to the presence of multiple voice selective activity clusters along the left and right STG/STS, these face selective responses are spatially more confined. However, an interesting goal for further research would be to relate voice and face development at an individual subject basis by a fine-grained characterization of recognition performance and voice/face selective activity (e.g. lateralization, variability, selectivity, area and response amplitude).

A second main goal of this study was to delineate developmental changes in inter-individual variability of STC anatomy and function. Our data provide first evidence for a hemisphere specific (right STC) increase in anatomical as well as functional variability. Although a comparison of infant and adult brains indicates substantial and regionally specific differences in cortical expansion and folding patterns (Hill et al., 2010b), and cortical gray-matter development shows a regionally specific progression from childhood to adulthood (Gogtay et al., 2004), little is known about developmental changes in sulcal/gryal trajectories during childhood and adolescence. Our individually traced cortical surface landmarks indicate a specific developmental increase in inter-subject variability of the trajectory of the STS in the right but not in the left hemisphere. A similar pattern was observed for the right PT, but not for the STG or FTS. Such a protracted developmental change in right STS trajectory (and right PT variability) may occur as a result of experience-dependent plasticity and extends previous reports of prominent developmental changes in the right versus left Sylvian fissure across the same age groups (Sowell et al., 2002) and of enhanced inter-subject variability in the trajectory of the right as compared to left STS in adults (Im et al., 2010). It is important to note that in the right hemisphere, the expected variability of HG morphology was constant across age groups (see Supplementary Fig. 1), making it highly unlikely that this source of variability underlies the developmental increase in variability of the right STC.

The age-related increase in variability of anatomically aligned right superior temporal fMRI responses to voices, other natural categories and tones follows the pattern of anatomical findings in this region. A developmental increase in functional and anatomical variability suggests a special role of the right STC in coding individual differences in auditory perception that are enhanced by unique experience during development. This may relate to individual differences in exposure to auditory categories that strongly involve the right STC areas such as 
music (Klein and Zatorre, 2011) and extracting speaker identity (Belin et al., 2004) or paralinguistic information (Schirmer and Kotz, 2006) from speech. More homogeneous maturational and/or learning related factors, in particular language exposure, on the other hand may lead to a more consistent development of homologue areas in the left superior temporal cortex. This notion would be consistent with the absence of a developmental increase in inter-subject variability in the left STC, and more specifically, with the observation of (1) greater variability of the FTS and STG in the left as compared to the right hemisphere in children, and (2) larger variability of left STC activity to tones in children and adolescents as compared to adults. Although the above framework of a unique and variable development of the right STC together with a stable development of left STC fits with our morphological as well as functional data, it leaves one of our findings unexplained, i.e. a smaller variability of left STC responses to other categories in children as compared to adolescents and adults.

We observed significant effects of development on both morphological and functional traits of the STC using a cross-sectional design with 10 subjects per age group ( 8 for functional data of children). In cross-sectional comparisons, however, it is not possible to exclude the influence of cross-group variance; it would thus be important to replicate the current findings in a larger longitudinal investigation. Another possible confounding factor in the current study concerns the relatively higher female/male ratio in the children and adolescent groups ( 8 females, versus 6 females in the adult group). However, previous large scale studies did not find significant sex differences in the variability of neuroanatomical asymmetries including that of the PT and HG (Chiarello et al., 2009, see also Leonard et al., 1998). Thus, the effect of the unbalanced gender samples in our study is not expected to be large.

From a methodological point of view, our study emphasizes the importance of considering hemispheric and age group differences in inter-subject variability when carrying out group studies. Focussing the analysis on the cortical surface, as opposed to traditional volume based analysis (Talairach and MNI transformations), and applying tools such as cortex-based alignment greatly reduces this variability (see also Desai et al., 2005; Frost and Goebel, 2012). Depending on the research question one may choose to further constrain this alignment procedure using a functional localizer (e.g. tonotopic map) for inter-subject alignment. This functional cortex-based alignment scheme may reduce the remaining inter-subject differences due to functional variability such as observed in the present study, and/or morphological differences that prevent anatomical alignment across subjects (e.g. different numbers of HGs).

In conclusion, the present study reveals regionally specific structural and functional developmental differences within the right superior temporal cortex of children, adolescents and adults. Such an extended developmental time course indicates a prolonged process of functional specialization during which auditory input contributes to the shaping and fine tuning of relevant brain circuitry (Johnson, 2003). Age-related refinement of voice perception may underlie the developmental decrease and focalization of the rightward asymmetry for voice selective fMRI responses. Unique individual exposure to auditory categories such as voices and music may contribute to the age-related increase in anatomical and functional right superior temporal variability.

\section{Acknowledgments}

This work was supported by the Netherlands Organization for Scientific Research (NWO) VENI-grant no. 451-07-002 to MB. We thank Jeannette Boschma and Annemarie Graus for assistance in data acquisition. We also thank all the parents and children for their participation and the St. Aloysius school, OBS de Perroen, Bernard Lievegoed School and the Porta Mosana College in Maastricht for their support.

\section{Conflict of interest}

The authors declare that there are no conflicts of interest.

\section{Appendix A. Supplementary data}

Supplementary data to this article can be found online at http:// dx.doi.org/10.1016/j.neuroimage.2013.07.017.

\section{References}

Annett, M., 1979. Family handedness in three generations predicted by the right shift theory. Ann. Hum. Genet. 42, 479-491.

Belin, P., Zatorre, R.J., Lafaille, P., Ahad, P., Pike, B., 2000. Voice-selective areas in human auditory cortex. Nature 403, 309-312.

Belin, P., Fecteau, S., Bedard, C., 2004. Thinking the voice: neural correlates of voice perception. Trends Cogn. Sci. 8, 129-135.

Binder, J.R., Frost, J.A., Hammeke, T.A., Bellgowan, P.S., Springer, J.A., Kaufman, J.N., Possing, E.T., 2000. Human temporal lobe activation by speech and nonspeech sounds. Cereb. Cortex 10, 512-528.

Blasi, A., Mercure, E., Lloyd-Fox, S., Thomson, A., Brammer, M., Sauter, D., Deeley, Q., Barker, G.J., Renvall, V., Deoni, S., Gasston, D., Williams, S.C., Johnson, M.H., Simmons, A., Murphy, D.G., 2011. Early specialization for voice and emotion processing in the infant brain. Curr. Biol. 21, 1220-1224.

Blomert, L., Vaessen, A., 2009. Differentiaal Diagnostiek van Dyslexie: Cognitieve analyse van lezen en spellen (Dyslexia Differential Diagnosis: Cognitive analysis of reading and spelling). Boom Test Publishers, Amsterdam.

Bonte, M., Blomert, L., 2004. Developmental changes in ERP correlates of spoken word recognition during early school years: a phonological priming study. Clin. Neurophysiol. 115, 409-423.

Campain, R., Minckler, J., 1976. A note on the gross configurations of the human auditory cortex. Brain Lang. 3, 318-323.

Chiarello, C., Welcome, S.E., Halderman, L.K., Towler, S., Julagay, J., Otto, R., Leonard, C.M., 2009. A large-scale investigation of lateralization in cortical anatomy and word reading: are there sex differences? Neuropsychology 23, 210-222.

Dehaene-Lambertz, G., Dehaene, S., Hertz-Pannier, L., 2002. Functional neuroimaging of speech perception in infants. Science 298, 2013-2015.

Dehaene-Lambertz, G., Montavont, A., Jobert, A., Allirol, L., Dubois, J., Hertz-Pannier, L., Dehaene, S., 2010. Language or music, mother or Mozart? Structural and environmental influences on infants' language networks. Brain Lang. 114, 53-65.

Desai, R., Liebenthal, E., Possing, E.T., Waldron, E., Binder, J.R., 2005. Volumetric vs. surface-based alignment for localization of auditory cortex activation. Neurolmage 26, 1019-1029.

Dorsaint-Pierre, R., Penhune, V.B., Watkins, K.E., Neelin, P., Lerch, J.P., Bouffard, M., Zatorre, R.J., 2006. Asymmetries of the planum temporale and Heschl's gyrus: relationship to language lateralization. Brain 129, 1164-1176.

Dubois, J., Benders, M., Lazeyras, F., Borradori-Tolsa, C., Leuchter, R.H., Mangin, J.F., Huppi, P.S., 2010. Structural asymmetries of perisylvian regions in the preterm newborn. Neurolmage 52, 32-42.

Durston, S., Davidson, M.C., Tottenham, N., Galvan, A., Spicer, J., Fossella, J.A., Casey, B.J., 2006. A shift from diffuse to focal cortical activity with development. Dev. Sci. 9, $1-8$.

Eckert, M.A., Leonard, C.M., Possing, E.T., Binder, J.R., 2006. Uncoupled leftward asymmetries for planum morphology and functional language processing. Brain Lang. 98, 102-111.

Fischl, B., Sereno, M.I., Tootell, R.B., Dale, A.M., 1999. High-resolution intersubject averaging and a coordinate system for the cortical surface. Hum. Brain Mapp. 8, $272-284$

Formisano, E., De Martino, F., Bonte, M., Goebel, R., 2008. "Who" is saying "what"? Brain-based decoding of human voice and speech. Science 322, 970-973.

Frost, M.A., Goebel, R., 2012. Measuring structural-functional correspondence: spatial variability of specialised brain regions after macro-anatomical alignment. Neurolmage 59, 1369-1381.

Geschwind, N., Levitsky, W., 1968. Human brain: left-right asymmetries in temporal speech region. Science 161, 186-187.

Glasel, H., Leroy, F., Dubois, J., Hertz-Pannier, L., Mangin, J.F., Dehaene-Lambertz, G., 2011. A robust cerebral asymmetry in the infant brain: the rightward superior temporal sulcus. NeuroImage 58, 716-723.

Goebel, R., Esposito, F., Formisano, E., 2006. Analysis of functional image analysis contest (FIAC) data with BrainVoyager QX: from single-subject to cortically aligned group general linear model analysis and self-organizing group independent component analysis. Hum. Brain Mapp. 27, 392-401.

Gogtay, N., Giedd, J.N., Lusk, L., Hayashi, K.M., Greenstein, D., Vaituzis, A.C., Nugent III, T.F., Herman, D.H., Clasen, L.S., Toga, A.W., Rapoport, J.L., Thompson, P.M., 2004. Dynamic mapping of human cortical development during childhood through early adulthood. Proc. Natl. Acad. Sci. U. S. A. 101, 8174-8179.

Golarai, G., Ghahremani, D.G., Whitfield-Gabrieli, S., Reiss, A., Eberhardt, J.L., Gabrieli, J.D., Grill-Spector, K., 2007. Differential development of high-level visual cortex correlates with category-specific recognition memory. Nat. Neurosci. 10, 512-522.

Golarai, G., Liberman, A., Yoon, J.M., Grill-Spector, K., 2010. Differential development of the ventral visual cortex extends through adolescence. Front. Hum. Neurosci. 3, 80.

Golestani, N., Price, C.J., Scott, S.K., 2011. Born with an ear for dialects? Structural plasticity in the expert phonetician brain. J. Neurosci. 31, 4213-4220. 
Grossmann, T., Oberecker, R., Koch, S.P., Friederici, A.D., 2010. The developmental origins of voice processing in the human brain. Neuron $65,852-858$.

Hill, J., Dierker, D., Neil, J., Inder, T., Knutsen, A., Harwell, J., Coalson, T., Van Essen, D. 2010a. A surface-based analysis of hemispheric asymmetries and folding of cerebral cortex in term-born human infants. J. Neurosci. 30, 2268-2276.

Hill, J., Inder, T., Neil, J., Dierker, D., Harwell, J., Van Essen, D., 2010b. Similar patterns of cortical expansion during human development and evolution. Proc. Natl. Acad. Sci. U. S. A. 107, 13135-13140.

Im, K., Jo, H.J., Mangin, J.F., Evans, A.C., Kim, S.I., Lee, J.M., 2010. Spatial distribution of deep sulcal landmarks and hemispherical asymmetry on the cortical surface. Cereb. Cortex 20, 602-611.

Johnson, M.H., 2003. Development of human brain functions. Biol. Psychiatry 54, 1312-1316.

Karni, A., Meyer, G., Rey-Hipolito, C., Jezzard, P., Adams, M.M., Turner, R., Ungerleider, L.G., 1998. The acquisition of skilled motor performance: fast and slow experience-driven changes in primary motor cortex. Proc. Natl. Acad. Sci. U. S. A. $95,861-868$.

Kilian-Hutten, N., Valente, G., Vroomen, J., Formisano, E., 2011. Auditory cortex encodes the perceptual interpretation of ambiguous sound. J. Neurosci. 31, $1715-1720$.

Kim, J.J., Crespo-Facorro, B., Andreasen, N.C., O'Leary, D.S., Zhang, B., Harris, G., Magnotta, V.A., 2000. An MRI-based parcellation method for the temporal lobe. NeuroImage 11, 271-288.

Klein, M.E., Zatorre, R.J., 2011. A role for the right superior temporal sulcus in categorical perception of musical chords. Neuropsychologia 49, 878-887.

Kort, W., Schittekatte, M., Dekker, P.H., Verhaeghe, P., Compaan, E.L., Bosmans, M., Vermeir, G., 2005. WISC-III NL. Harcourt Test Publishers, London.

Kriegeskorte, N., Goebel, R., 2001. An efficient algorithm for topologically correct segmentation of the cortical sheet in anatomical MR volumes. NeuroImage 14, 329-346.

Leonard, C.M., Puranik, C., Kuldau, J.M., Lombardino, L.J., 1998. Normal variation in the frequency and location of human auditory cortex landmarks. Heschl's gyrus: where is it? Cereb. Cortex 8, 397-406.

Leonard, C., Eckert, M., Given, B., Virginia, B., Eden, G., 2006. Individual differences in anatomy predict reading and oral language impairments in children. Brain 129, 3329-3342.
Obleser, J., Zimmermann, J., Van Meter, J., Rauschecker, J.P., 2007. Multiple stages of auditory speech perception reflected in event-related FMRI. Cereb. Cortex 17, 2251-2257.

Ochiai, T., Grimault, S., Scavarda, D., Roch, G., Hori, T., Riviere, D., Mangin, J.F., Regis, J. 2004. Sulcal pattern and morphology of the superior temporal sulcus. Neurolmage 22, 706-719.

Ono, M., Kubik, S., Abernathey, C., 1990. Atlas of the Cerebral Sulci. Thieme, Stuttgart/ New York.

Pantazis, D., Joshi, A., Jiang, J., Shattuck, D.W., Bernstein, L.E., Damasio, H., Leahy, R.M. 2010. Comparison of landmark-based and automatic methods for cortical surface registration. NeuroImage 49, 2479-2493.

Parviainen, T., Helenius, P., Poskiparta, E., Niemi, P., Salmelin, R., 2011. Speech perception in the child brain: cortical timing and its relevance to literacy acquisition. Hum. Brain Mapp. 32, 2193-2206.

Schirmer, A., Kotz, S.A., 2006. Beyond the right hemisphere: brain mechanisms mediating vocal emotional processing. Trends Cogn. Sci. 10, 24-30.

Schneider, P., Scherg, M., Dosch, H.G., Specht, H.J., Gutschalk, A., Rupp, A., 2002. Morphology of Heschl's gyrus reflects enhanced activation in the auditory cortex of musicians. Nat. Neurosci. 5, 688-694.

Scott, S.K., Blank, C.C., Rosen, S., Wise, R.J., 2000. Identification of a pathway for intelligible speech in the left temporal lobe. Brain 123 (Pt 12), 2400-2406.

Shapleske, J., Rossell, S.L. Woodruff, P.W., David, A.S., 1999. The planum temporale: systematic, quantitative review of its structural, functional and clinical significance. Brain Res. Brain Res. Rev. 29, 26-49.

Sowell, E.R., Thompson, P.M., Rex, D., Kornsand, D., Tessner, K.D., Jernigan, T.L., Toga, A.W. 2002. Mapping sulcal pattern asymmetry and local cortical surface gray matter distribution in vivo: maturation in perisylvian cortices. Cereb. Cortex 12, 17-26.

Talairach, J., Tournoux, P., 1980. Co-planar Stereotaxic Atlas of the Human Brain. Thieme, Stuttgart.

Van Essen, D.C., 2005. A Population-Average, Landmark- and Surface-based (PALS) atlas of human cerebral cortex. Neurolmage 28, 635-662.

von Kriegstein, K., Eger, E., Kleinschmidt, A., Giraud, A.L., 2003. Modulation of neural responses to speech by directing attention to voices or verbal content. Brain Res. Cogn. Brain Res. 17, 48-55.

Wechsler, D., Van der Steene, G., Vertommen, H., Bleichrodt, N., Uiterwijk, J.M., 2000 WAIS-III NL. Swets \& Zeitlinger, Lisse. 